\title{
ANALISIS PENGARUH ESKPOR, NILAI TUKAR RUPIAH, DAN UTANG LUAR NEGERI TERHADAP CADANGAN DEVISA INDONESIA
}

\author{
Adinda Marethasya Fortuna', Sri Muljaningsih ${ }^{2}$, Kiki Asmara ${ }^{3}$ \\ ${ }^{1,2,3}$ Program Studi Ekonomi Pembangunan, Fakultas Ekonomi dan Bisnis, \\ Universitas Pembangunan Nasional "Veteran" Jawa Timur, \\ Surabaya, Indonesia \\ amarethasya@gmail.com
}

\begin{abstract}
Abstrak
Indonesia adalah negara dengan sistem perekonomian terbuka. Penerapan sistem perekonomian terbuka memiliki kaitan erat dengan kegiatan perdagangan internasional yang berperan penting untuk membantu negara memenuhi kebutuhan dalam negerinya. Pembiayaan keagiatan perdagangan internasional yang dilakukan Indonesia bersumber dari cadangan devisa. Penelitian ini bertujuan untuk mengetahui pengaruh Ekspor, Nilai Tukar Rupiah, dan Utang Luar Negeri terhadap Cadangan Devisa Indonesia. Data yang peneliti gunakan dalam penelitian ini ialah data sekunder selama 15 tahun yakni mulai dari tahun 2005 hingga pada tahun 2019 yang diperoleh dari Badan Pusat Statistik, Bank Indonesia, dan World Bank. Penelitian ini menggunakan analisis deskriptif kuantitatif dan alat analisis yang digunakan adalah analisis regresi linier berganda dengan menggunakan program computer SPSS 13. Hasil dari analisis memperlihatkan bahwa Ekspor, Nilai Tukar Rupiah, dan Utang Luar Negeri secara bersama sama atau simultan berpengaruh terhadap Cadangan Devisa Indonesia. Secara individu atau parsial Ekspor dan Utang Luar Negeri berpengaruh signifikan dan positif terhadap Cadangan Devisa Indonesia. Sedangkan Nilai Tukar Rupiah secara parsial berpengaruh signifikan dan negative terhadap Cadangan Devisa Indonesia.
\end{abstract}

Kata Kunci: Cadangan Devisa Indonesia, Ekspor, Nilai Tukar Rupiah, Utang Luar Negeri

\begin{abstract}
Indonesia is a country with an open economic system. The implementation of an open economic system is closely related to international trade activities which play an important role in helping countries meet their domestic needs. The financing of international trade activities carried out by Indonesia comes from foreign exchange reserves. This study aims to determine the effect of exports, rupiah exchange rate, and foreign debt on Indonesia's foreign exchange reserves. The data that the researcher uses in this study is secondary data for 15 years, starting from 2005 to 2019 which was obtained from the Central Statistics Agency, Bank Indonesia, and the World Bank. This study uses quantitative descriptive analysis and the analytical tool used is multiple linear regression analysis using the SPSS 13 computer program. The results of the analysis show that exports, rupiah exchange rates, and foreign debt simultaneously or simultaneously affect Indonesia's foreign exchange reserves. Individually or partially, Exports and External Debt have a significant and positive effect on Indonesia's Foreign Exchange Reserves. While the Rupiah Exchange Rate partially has a significant and negative effect on Indonesia's Foreign Exchange Reserves.
\end{abstract}

Keywords: Foreign Exchange Reserves, Export, Exchange Rate, Foreign Debt 


\section{PENDAHULUAN}

Indonesia adalah negara dengan sistem perekonomian terbuka sejak tahun 1982. Penerapan sistem perekonomian terbuka memiliki kaitan erat dengan kegiatan perdagangan internasional yang berperan penting untuk membantu negara memenuhi kebutuhan dalam negerinya yang tidak semua dapat diproduksi di negaranya. Definisi dari perdagangan internasional sendiri adalah perdagangan antar negara termasuk ekspor dan impor (Tambunan dalam Sonia dan Setiawina, 2016). Dengan dilakukannya perdagangan internasional, setiap negara dapat bertukar sumber daya dari tiap-tiap negara untuk pemenuhan kebutuhan domestik dan berkontribusi terhadap pertumbuhan ekonomi domestik maupun pertumbuhan ekonomi dunia. Pembiayaan kegiatan perdagangan internasional yang dilakukan Indonesia bersumber dari cadangan devisa yang berada di bawah tanggung jawab Bank Indonesia sehingga transaksinya tercatat dalam neraca pembayaran Bank Indonesia (Putri dkk ,2017).

Menurut Salvatore (2014), Cadangan devisa (International Reserves) dapat dijelaskan sebagai asset liquid sebuah negara yang diakui nilainya secara internasional yang memiliki harga tinggi dan dapat menjadi alat pembayaran dalam transaksi perdagangan internasional.

Menurut Hady dalam Sonia dan Setiawina (2016), cadangan devisa yaitu aktiva asing dan bank devisa milik pemerintah yang pengelolaannya harus dilakukan dengan tujuan memenuhi kebutuhan transaksi internasional. Cadangan devisa juga merupakan salah satu nilai ukur penilaian aktivitas perdagangan internasional sebuah negara, selain itu juga menjadi tolak ukur fundamental ekonomi sebuah negara.

Sistem devisa bebas ialah sistem yang digunakan Indonesia sebagai kebijakan cadangan devisanya, kebijakan ini membebaskan jumlah uang yang boleh dibawa keluar atau masuk Indonesia. Kebijakan devisa Indonesia digunakan untuk menjaga kondisi perekonomian serta meningkatkan dan mengendalikan eskpor dan impor, menjaga kestabilan pasar dan juga kestabilan kurs (Subandi dalam Putri dkk, 2017).

Besarnya cadangan devisa milik suatu negara dapat menjadi cerminan kemampuan suatu negara tersebut untuk melakukan aktivitas perdagangan internasional karena sebenarnya besaran cadangan devisa negara ditentukan oleh salah satunya aktivitas perdagangan internasional, contohnya ekspor dan impor, serta arus modal dalam bentuk bantuan finansial atau hutang dari negara lain dan penanaman modal asing dalam negeri (Gandhi dalam Putri dkk, 2017).

Status cadangan devisa disebut aman jika jumlah cadangan devisa negara tersebut setidaknya dapat memenuhi kebutuhan impor negaranya dalam periode 3 bulan, sesuai dengan standar kecukupan internasional. Berdasarkan data cadangan devisa Indonesia oleh Bank Indonesia tahun 2016-2019 cenderung mengalami fluktuasi namun tidak terlalu tajam. Pada tahun 2016 indonesia memiliki cadangan devisa sebesar US\$ 116.362 juta. Lalu pada tahun 2017 menjadi US\$130.196,38 Juta atau terjadi peningkatan sebesar $11.89 \%$. Kemudian pada tahun 2018 terjadi penurunan sebesar $7.33 \%$ menjadi 120.654,27 Juta US\$ dan kembali mengalami peningkatan sebesar $7.07 \%$ menjadi 129.183,28 Juta US\$ pada tahun 2019.

Ekspor merupakan salah satu sumber cadangan devisa dikarenakan saat terjadinya transaksi ekspor, negara akan mendapatkan pemasukan dalam bentuk valuta asing. Jika jumlah ekspor naik maka cadangan devisa akan naik pula (Reny dan Agustina, 2014). Dalam data ekspor dari Badan Pusat Statistik (BPS) tahun 2016-2019 menunjukkan bahwa pada tahun 2016 total ekspor Indonesia adalah sebesar 144.489,7 Juta US\$. Di tahun selanjutnya, total ekspor Indonesia meningkat menjadi $168.828,2$ Juta US\$ atau dengan kata lain terjadi peningkatan $16.84 \%$. Lalu di 2018 total ekspor Indonesia meningkat $6.62 \%$ menjadi $180.012,7$ Juta US\$. Kemudian mengalami penurunan pada tahun 2019 menjadi 167.683 Juta US\$ atau terjadi penurunan sebesar $6.85 \%$.

Menurut Sukirno (2015) definisi nilai tukar rupiah yaitu jumlah uang domestik dengan funsgi guna membeli satu unit mata uang asing. Apresiasi ataupun depresiasi nilai tukar rupiah memberikan dampak langsung terhadap neraca transaksi berjalan, yang juga berpengaruh terhadap jumlah cadangan devisa. Apabila terjadi pelemahan kurs nilai tukar rupiah (depresiasi) maka negara memperlukan lebih banyak devisa agar dapat melaksanakan transaksi internasional (Jalunggono, Cahyani, dan Juliprijanto, 2020). Berdasarkan data nilai tukar rupiah dari tahun 2016 hinga tahun 2019 yang diperoleh dari Bank Indonesia, di tahun 2016 nilai tukar rupiah terhadap dolar adalah Rp. 13.436. Lalu di tahun berikutnya sebesar Rp. 13.548 atau terjadi depresiasi sebesar $0.83 \%$. Kemudian di tahun 2018 adalah sebesar Rp. 14.481 atau terjadi depresiasi sebesar $6.89 \%$ dan pada tahun 2019 terjadi apresiasi nilai tukar rupiah sebesar $4.01 \%$ menjadi Rp. 13.901.

Menurut Atmadja (2000), utang luar negeri dapat meningkatkan jumlah cadangan devisa maupaun investasi suatu negara sehingga dapat merangsang pertumbuhan ekonomi suatu negara. Pengukuran beban utang luar negeri dilakukan dengan menilai proporsi penerimaan devisa pada current account ekspor yang diserap oleh debt service. Dari data utang luar negeri tahun 2016-2019 oleh Bank Indonesia, di tahun 2016 utang luar negeri Indonesia adalah US\$ 320.006 Juta. Dan di 2017 sebesar 352.469 Juta US\$ atau terjadi kenaikan $10.14 \%$ dari tahun sebelumnya. Lalu pada tahun 2018 terjadi peningkatan sebesar $6.51 \%$ menjadi 
375.430 Juta US\$. Dan pada tahun 2019 juga mengalami peingkatan sebesar $7.69 \%$ menjadi $404.315 \%$.

Berdasarkan fenomena yang telah diuraikan diatas maka tujuan penulis dalam melakukan penelitian ini adalah untuk mengetahui pengaruh ekspor, nilai tukar rupiah, dan utang luar negeri terhadap cadangan devisa Indonesia pada tahun 2005-2019.

\section{TINJAUAN PUSTAKA}

\section{Cadangan Devisa}

Cadangan devisa yaitu valuta asing untuk pendanaan pembangunan dan pelunasan kewajiban ke luar negeri, termasuk pembiayaan impor dan lainnya dan dikelola oleh bank sentral (Tambunan, 2001).

Berdasarkan konsep international reserves and foreign currency liquidity (IRFCL) oleh IMF, cadangan devisa adalah seluruh aktifitas luar negeri oleh otoriter moneter dan sewaktu-waktu dapat dialihgunakan untuk pendanaan balance of payment melalui intervensi di pasar valuta asing (Gandhi, 2006).

Terdapat dua terminologi cadangan devisa yang dikenal dalam perkembangan ekonomi Indonesia. Pertama, official foreign exchanges reserve adalah cadangan devisa negara yang dikelola bank sentral sesuai UU No. 13 Tahun 1968. Kedua, country foreign exchanges reserve mencakup seluruh devisa dengan kepemilikan badan yang termasuk sebagai kekayaan nasional (Halwani, 2005).

\section{Sistem Sistem Cadangan Devisa}

Sistem devisa didirikan oleh Bank Indonesia utnuk mengatur pergerakan devisa dari beberapa negara terbagi menjadi tiga yaitu:

1. Sistem Devisa Kontrol

Dalam sistem ini, devisa dimiliki negara, termasuk devisa milik masyarakat, sehingga kepemilikan dari devisa harus mendapatkan izin dari negara. Indonesia pernah menerapkan sistem ini berdasarkan UU no. 32 tahun 1964.

2. Sistem Devisa Semi Bebas

Sistem ini menganut bahwa terdapat beberapa jenis perolehan dan penggunaan devisa tertentu yang harus diberikan ke dan diizinkan oleh Bank Indonesia dan ada juga jenis devisa lain yang dibebaskan. Sistem ini sempat diatur dalam Perpu No. 64 tahun 1970.

3. Sistem Devisa Bebas

Indonesia menganut system ini sesuai dengan PP No. 1 Tahun 1982 yang menyatakan bahwa perolehan dan penggunaan devisa oleh masyarakat adalah bebas dan tidak wajib utnuk melaporkan perolehan devisanya.

\section{Sumber Sumber Cadangan Devisa}

Menurut Amir (2004), secara garis besar pengelompokkan sumber cadangan devisa yaitu:

1. Ekspor

Hasil kegiatan ekspor baik barang, baik komoditas maupun non-komoditas ataupun sektor jasa.

2. Pinjaman Luar Negeri

Pinjaman dana dari negara asing, Lembaga negeri maupun swasta berskala internasional seperti Inter-Governmental Group on Indonesia (IGGI), World Bank, Asia Development Bank dan lainnya.

3. Hadiah dan Hibah dari Luar Negeri Hadiah dan hibah dapat diperoleh dari PBB seperti UNDP dan UNESCO.

4. Laba Penanaman Modal Luar Negeri Laba dari penanaman modal yang berasal dari investasi oleh investor luar negeri, termasuk laba yang ditransfer, dan pengiriman dana dari WNI dari luar Indonesia.

5. Pariwisata

Hasil dari kegiatan dari wisatawan dari luar negeri maupun domestic. Semakin banyak wisatawan, semakin meningkat pula devisa yang akan diterima.

\section{Ekspor}

Menurut Amir (2004), ekspor adalah kegiatan menyisihkan sejumlah barang dari peredaran di dalam negeri untuk mengirimkan barang tersebut ke luar negeri untuk memperoleh pembayaran dalam bentuk valuta asing yang terlah diatur dalam ketentuan yang sudah ditetapkan oleh pemerintah.

Definisi dari ekspor adalah kegiatan penjualan barang, jasa, atau modal dari dan ke daerah kepabeaan yang berbeda. Sedangkan pengertian dari daerah pabean adalah merujuk kepada seluruh wilayah negara yang sudah diakui secara internasional (Purwito dan Indriani, 2015).

Kegiatan ekspor sangat bergantung pada kemampuan bersaing suatu produk dalam pasar luar negeri. Berhubungan dengan hal tersebut, ekspor berpengaruh langsung terhadap pendapatan nasional. Namun, meningkatnya pendapatan nasional tidak selalu membantu meningkatkan jumlah ekspor karena terdapat variabel eksternal lainnya yang tidak berkaitan dengan aktivitas ekspor (Sukirno, 2008). Ekspor neto ialah selisih dari total ekspor dengan total impor yang dilakukan oleh suatu negara. Jika angkanya positif, artinya ekspornya lebih besar dibanding impornya dan sebaliknya (Case dan Fair, 2007). 


\section{Hubungan Ekspor Dengan Cadangan Devisa}

Menurut Todaro (2011) negara pasti akan mendapat sejumlah uang dalam bentuk devisa melalui kegiatan ekspor. Penelitian oleh Kuswantoro (2017) menyatakan ekspor memiliki pengaruh positif dan signifikan terhadap cadangan devisa.

\section{Nilai Tukar Rupiah}

Dalam perdagangan internasional, nilai tukar mata uang penting karena exchange rate membantu untuk membandingkan harga (Santana dan Adiyadnya, 2017). Definisi dari kurs valuta asing sendiri adalah jumlah uang domestik yang jumlahnya dapat bernilai sama dengan satu unit mata uang asing (Murni, 2016).

Kurs adalah harga mata uang domestik yang diukur nilainya dalam mata uang lainnya sehingga berperan penting dalam pembuatan keputusan pembelaanjaan barang dengan nilai mata uang asing (Juniantara dan Sri, 2013).

Menurut Reny dan Agustina (2014), nilai tukar ialah harga relative suatu mata uang terhadap mata uang lainnya. Apabila suatu negara mengalami apresiasi maka akan menurunkan ekspornya.

Para ahli ekonomi membagi nilai tukar menjadi nominal exchange rate yang merupakan suatu nilai di mana seseorang dapat memperdagangkan mata uang tersebut. Satu lainnya adalah real exchange rate yaitu nilai jual-beli suatu negara ke negara lain (Mankiw, 2012).

Terdapat kaitan erat antara nilai tukar mata uang dengan valuta asing. Dolar amerika sebagai mata uang standar dalam perdangaan internasional membawa dampak pada kegiatan impor ekspor. Saat kurs dollar naik, maka eksportir sebaiknya memperbanyak ekspor untuk memperoleh lebih banyak rupiah, sehingga saat nilai kurs dollar amerika menguat, ekspor dan valas serta cadangan devisa juga meningkat (Santana dan Adiyadnya, 2017).

\section{Hubungan Nilai Tukar Rupiah Dengan Cadangan Devisa}

Nilai tukar mata uang berguna sebagai satuan alat pembayaran transaksi internasional. Manurung (2016) menjelaskan ketika cadangan devisa meningkat, nilai tukar uang domestic mengalami apresiasi dan menjadi salah satu indikator pertumbuhan ekonomi dan memungkinkan untuk dapat memperoleh lebih banyak devisa.

\section{Utang Luar Negeri}

Pemberian utang luar negeri berawal dari pasca Perang Dunia II bertujuan memberikan pinjaman kepada negara-negara dunia ketiga, salah satunya Indonesia untuk membiayai pembangunan dan defisit anggaran. Definisi dari utang luar negeri adalah setiap penerimaan negara baik dalam bentuk devisa dari peminjam yang harus dikembalikan dengan syarat tertentu (Machmud, 2016)

Utang luar negeri dibutuhkan untuk membiayai pembangunan infrastruktur, pembiayaan bunga utang, pembiayaan bencana, penguatan posisi keuangan, dan merupakan bentuk akibat dari kurangnya cadangan keuangan untuk transaksi perdagangan suatu negara (Togatorop dan Setiawina, 2017). Untuk stabilisasi kondisi perekonomian Indonesia, salah satu dari upaya negara adalah dengan mengambil kebijakan ekonomi utnuk berutang kepada negara atau lembaga keuangan internasional (Majid, 2013).

Berdasarkan pandangan tradisional, utang pemerintah berpotensi membawa dapak tamahan seperti defisit anggaran yang membesar sehinga terjadi ekspansi moneter yang berlebihan peningkatan inflasi (Mankiw, 2007).

Utang luar negeri umumnya memiliki sifat sukarela, namun sifat ini tidak berlaku apabila terdapat suatu negara yang memiliki kekuasaan atas negara lain. Utang luar negeri meliputi pengalihan dana dari negara yang memberikan pinjaman atau yang biasa disebut dengan kreditur ke negara yang menerima pinjaman atau biasa disebut dengan debitur pada saat terjadinya utang. Utang luar negeri juga bisa berubah menjadi utang dalam negeri ketika penduduk negara debitur membeli surat surat berharga dari negara kreditur (Irawan dan Suparmoko, 2016).

\section{Hubungan Utang Luar Negeri Dengan Cadangan Devisa}

Todaro (2011), utang luar negeri memang dapat menambah cadangan devisa namun tentu juga akan menambah akumulasi utang. Penelitian Kuswantoro (2017) menyatakan utang luar negeri berpengaruh positif dan signifikan terhadap cadangan devisa.

\section{METODE PENELITIAN}

\section{Pendekatan Penelitian, Tempat dan Waktu Penelitian}

Dalam melakukan pengamatan ini digunakan metode kuantitatif untuk menguji hipotesis sebagai variabel yang telah ditentukan menekankan pada data numerikal yang diolah dengan model statistik (Habibi dan Hidayat R, 2017).

Lokasi penelitian ini adalah seluruh wilayah di Indonesia dan telah disesuaikan oleh BPS. Peneliti memilih Indonesia sebagai lokasi karena cadangan devisa Indonesia yang fluktuatif selama 15 tahun (2005-2019).

\section{Populasi dan Sampel}

Populasi ialah wilayah generalisasi atas objek atau subjek dengan kualitas dan karakteristik tertentu yang peneliti sudah tetapkan untuk penulis pelajari dan simpulkan (Sugiyono, 2011). Dalam 
penelitian ini, populasinya adalah seluruh cadangan devisa, ekspor, nilai tukar rupiah, dan utang luar negeri. Di sisi lain, sampel adalah bagian dari populasi (Sugiyono, 2011). Dalam penelitian ini, sampelnya adalah data cadangan devisa Indonesia, ekspor, nilai tukar rupiah, dan utang luar negeri tahun 2005-2019.

\section{Jenis, Sumber, dan Teknik Pengumpulan Data}

Penelitian ini menggunakan data sekunder dengan bentuk time series tahun 2005-2019 yang diperoleh secara tidak langsung dari perusahaan, lembaga ataupun instansi terkait yang telah dipublikasikan secara resmi.

Data untuk penelitian ini diperoleh dari instansi dan lembaga yang berkaitan, yaitu Badan Pusat Statistik (BPS) untuk data ekspor, Bank Indonesia (BI) untuk data cadangan devisa dan nilai tukar rupiah, World Bank untuk data utang luar negeri.

Untuk melakukan penelitian ini, Peneliti melakukan studi kepustakaan dengan mengumpulkan data dari jurnal penelitian terdahulu, kemudian mencatatnya, kemdian penulis juga mengambil data numerikal dari sumber data yang sudah disebutkan.

\section{Teknik Analisis}

Teknik analisis data ialah metode pengumpulan data atau pengumpulan variabel yang digunakan dimana didalamnya terdapat analisis penting dan harus dipahami oleh peneliti. Kemudian data dianalisis dengan metode kuantitatif dimana data yang didapat diperoleh dalam bentuk angka dengan melakukan perhitungan berdasarkan teori teori yang sudah ada. Dalam penelitian ini datanya adalah adalah data time series selama 15 tahun (2005-2019).

Peneliti menggunakan analisis regresi berganda dengan asumsi BLUE (Best Linier Unbiased Estimate) untuk menganalisis pengaruh yang telah disebutkan dalam hipotesis. Hal ini diperlukan untuk mengetahui kebenaran koefisien pada persamaan dengan bantuan SPSS (Statistic Program For Social Science) versi 13.0 dengan perumusan persamaan sebagai berikut:

$$
\mathrm{Y}=\mathrm{a}+\beta 1 \mathrm{X} 1+\beta 2 \mathrm{X} 2+\beta 3 \mathrm{X} 3
$$

Keterangan:

$\mathrm{Y}$

$\mathrm{X} 1$

$\mathrm{X} 2$

$\mathrm{X} 3$

$\beta 1, \beta 2, \beta 3$, 2013).

\section{HASIL DAN PEMBAHASAN}

Analisis Regresi Linear Berganda

Hasil uji analisis regresi linear berganda diperoleh persamaan sebagai berikut:

$$
Y=14726.119+\underset{007 X 3}{0.323 X 1}-5.736 X 2+3.73 E-
$$

Dari persamaan diatas maka dapat dijelaskan sebagai berikut

1. Hasil konstanta $(\beta 0)$ sebesar 14726.119 artinya ketika Ekspor (X1), Nilai Tukar Rupiah (X2), dan Utang Luar Negeri (X3) dianggap konstan maka nilai Cadangan Devisa Indonesia akan naik sebesar 14726.119 Juta US\$.

2. Koefisien regresi ( $\beta 1)$ sebesar 0.323 yang berarti bahwa apabila Ekspor (X1) naik sebesar 1 Juta US\$ maka Cadangan Devisa Indonesia (Y) akan naik sebesar 0,323 Juta US\$ dengan asumsi X2 dan X3 tetap atau konstan.

3. Koefisien regesi ( $\beta 2$ ) sebesar -5.736 artinya apabila Nilai Tukar Rupiah (X2) naik sebesar 1 Rupiah maka Cadangan Devisa Indonesia (Y) mengalami penurunan sebesar 5.736 Juta US\$ dengan asumsi X1 dan X3 konstan.

4. Koefisien regresi ( $\beta 3$ ) sebesar 3.73E-007 artinya apabila Utang Luar Negeri (X3) naik sebesar 1 US\$ maka Cadangan Devisa Indonesia akan naik sebesar 3.73E-007 Juta US\$ dengan asumsi X1 dan X2 konstan.

\section{Uji Asumsi Klasik}

Pengujian ini dilakukan untuk mendapatkan hasil BLUE yang harus memenuhi tiga asumsi dasar yaitu Autokorelasi, Multikolinieritas, dan Heterokedastisitas. Apabila, salah satu dari ketiga asumsi dasar ini dilanggar maka persamaan yang diperoleh tidak lagi bersifat BLUE yang akan menyebabkan pengambilan keputusan melalui Uji $\mathrm{F}$ dan Uji T menjadi tidak valid dan secara statistik dapat mengacaukan kesimpulan

\section{Uji Autokorelasi}

Tabel 1. Uji Autokorelasi

\begin{tabular}{|c|c|c|c|c|c|}
\hline Model & $R$ & $R$ Square & $\begin{array}{c}\text { Adjust } \\
\text { ed } R \\
\text { Square }\end{array}$ & $\begin{array}{c}\text { Std. Error of } \\
\text { the Estimate }\end{array}$ & $\begin{array}{c}\text { Durbin } \\
\text { Watson }\end{array}$ \\
\hline 1 &, $977^{\mathrm{a}}$ &, 954 &, 941 & 792858927 & 1,055 \\
\hline
\end{tabular}

Sumber: Data diolah peneliti (2021)

Hasil analisis uji autokorelasi pada penelitian ini diperoleh nilai DW test sebesar 1.055. Dalam persamaan ini, variabel bebas berjumlah 3 dan jumlah data (n) adalah 15. Maka, nilai DW tabel adalah $\mathrm{dL}=0.8140$ dan $\mathrm{dU}=1.7501$. Sehingga nilai DW test berada di antara dL dan dU atau berada 
dalam daerah keragu-raguan yang artinya tidak terdapat kesimpulan yang pasti dan perlu dilakukan runs test.

Runs test adalah bagian dari statistic nonparametrik untuk mengetahui tinggi korelasi antar residualnya. Hipotesis pengujian autokoelasi dengan menggunakan run test pada penelitian ini yaitu:

1.terjadi autokorelasi jika nilai signifikansi $<0,05$

2.tidak terjadi autokorelasi jika nilai signifikan > 0.05 (Ghozali Imam, 2013)

Tabel 2. Uji Autokorelasi Runs Test

\begin{tabular}{|l|c|}
\hline & $\begin{array}{c}\text { Unstandardized } \\
\text { Residual }\end{array}$ \\
\hline Test Value & -289.65197 \\
\hline Total Cases & 15 \\
\hline $\mathrm{Z}$ & -0.521 \\
\hline $\begin{array}{l}\text { Asymp Sig. (2- } \\
\text { Tailed) }\end{array}$ & 0.603 \\
\hline
\end{tabular}

Sumber: Output SPSS, 2021

Dari table diatas, nilai signifikansi sebesar 0.603 atau nilai sig $>0.05$. Maka kesimpulannya tidak ditemukan gejala autokorelasi dalam model, sehingga pengujian dapat dilanjutkan.

\section{Uji Multikolinearitas}

Tabel 3. Uji Multikolinearitas

\begin{tabular}{|l|c|c|}
\hline \multicolumn{1}{|c|}{ Variabel } & Tolerance & VIF \\
\hline Ekspor (X1) & 0,423 & 2,363 \\
\hline Nilai Tukar Rupiah (X2) & 0,149 & 6,700 \\
\hline Utang Luar Negeri (X3) & 0,104 & 9,629 \\
\hline
\end{tabular}

Sumber: Data diolah peneliti (2021)

Dari tabel diatas dapat dilihat bahwa variabel Ekspor (X1), Nilai Tukar Rupiah (X2), dan Utang Luar Negeri (X3) terbebas dari multikolinearistas karena memiliki nilai tolerance lebih dari 0,10 dan memiliki nilai VIF lebih kecil dari 10 sehingga dapat disimpulkan bahwa model regresi dapat dilanjutkan ketahap pengujian selanjutnya.

\section{Uji Heterokedastisitas}

Tabel 4. Tabel Heterokedastisitas

\begin{tabular}{|l|c|}
\hline \multicolumn{1}{|c|}{ Variabel } & Sig. (2-tailed) \\
\hline Ekspor (X1) & 0,934 \\
\hline Nilai Tukar Rupiah (X2) & 0,576 \\
\hline Utang Luar Negeri (X3) & 0,791 \\
\hline
\end{tabular}

Sumber: Data diolah peneliti (2021)

Dari tabel diatas dapat terlihat bahwa seluruh variabel yaitu variabel Ekspor (X1), Nilai Tukar Rupiah (X2), dan Utang Luar Negeri (X3) terbebas dari heterokedastisitas karena memiliki nilai signifikan diatas $5 \%$ sehingga dapat disimpulakn bahwa model regresi ini dapat dilanjutkan ketahap berikutnya.
Koefisien Determinasi $\left(\mathbf{R}^{2}\right)$

Tabel 5. Uji Koefisien Determinasi

\begin{tabular}{|c|c|c|c|c|}
\hline Model & $R$ & $R$ Square & $\begin{array}{c}\text { Adjusted } R \\
\text { Square }\end{array}$ & $\begin{array}{c}\text { Std. Error of the } \\
\text { Estimate }\end{array}$ \\
\hline 1 &, $977^{\mathrm{a}}$ &, 954 &, 941 & 7928,58972 \\
\hline
\end{tabular}

Sumber: Data diolah peneliti, 2021

Hasil analisis yang ditampilkan di tabel adalah R2 sebesar 0.954 yang mana variabel bebas mampu menjelaskan variabel terikat sebesar $95.4 \%$ dan sisanya dijelaskan oleh faktor diluar model.

\section{Uji F}

Tabel 6. Uji F Simultan (ANOVA)

\begin{tabular}{|c|l|l|c|c|c|c|}
\hline \multicolumn{2}{|c|}{ Model } & $\begin{array}{c}\text { Sum of } \\
\text { Square }\end{array}$ & $d f$ & $\begin{array}{c}\text { Mean } \\
\text { Square }\end{array}$ & $F$ & Sig. \\
\hline \multirow{2}{*}{1} & Regression & $1 \mathrm{E}+010$ & 3 & 4745593550 & 75,492 & \\
& & & & & &, $000^{\mathrm{b}}$ \\
\cline { 2 - 7 } & Residual & $7 \mathrm{E}+008$ & 11 & 62862535,02 & & \\
\cline { 2 - 7 } & Total & $1 \mathrm{E}+010$ & 14 & & & \\
\hline
\end{tabular}

Sumber: Data diolah peneliti (2021)

Pada Tabel. 6 Uji F Simultan ANOVA diatas diperoleh $\mathrm{f}$ hitung sebesar 75,492 dengan tingkat signifikan $0.000 \mathrm{a}$, sedangkan nilai f tabel $(\alpha=0,05)$ dengan degree of freedom (df1) adalah 3 (jumlah variabel bebas / k) dan (df2) adalah 11 (n-k1) maka diperoleh nilai f tabel sebesar 3,59. Dari hasil tersebut diketahi bahwa nilai f hitung $75.492>$ f tabel 3,59 yang artinya variabel ekspor, nilai tukar rupiah, dan uatng luar negeri berpengaruh secara simultan terhadap cadangan devisa Indonesia.

Uji t

Tabel 7. Uji t Parsial

\begin{tabular}{|l|c|c|}
\hline \multicolumn{1}{|c|}{ Variabel } & t Hitung & Sig. \\
\hline Ekspor (X1) & 3,270 & 0,007 \\
\hline $\begin{array}{l}\text { Nilai Tukar Rupiah } \\
\text { (X2) }\end{array}$ & $-2,208$ & 0,049 \\
\hline $\begin{array}{l}\text { Utang Luar Negeri } \\
\text { (X3) }\end{array}$ & 5,091 & 0,000 \\
\hline
\end{tabular}

Sumber: Data diolah peneliti (2021)

Uji $\mathrm{t}$ variabel Ekspor diperoleh nilai $\mathrm{t}$ hitung sebesar 3.270 sedangkan nilai $t$ tabel $(\alpha / 2$ $0.025)$ dengan deegre of freedom (df) adalah 11 (n$\mathrm{k}-1$ ) sehingga diperoleh $\mathrm{t}$ tabel sebesar 2,2009. Dari hasil tersebut diketahui bahwa nilai t hitung $3.270>$ $\mathrm{t}$ tabel 2.2009. Artinya, secara parsial ekspor berpengaruh signifikan dan positif terhadap cadangan devisa Indonesia.

Uji t variabel Nilai Tukar Rupiah diperoleh nilai $t$ hitung sebesar -2.208 sedangkan nilai t tabel $(\alpha / 2-0.025)$ dengan deegre of freedom (df) adalah 11 (n-k-1) sehingga diperoleh t tabel sebesar 2,2009. Dari dengan demikian diketahui bahwa nilai thitung $-2.208>$ t tabel 2.2009. Artinya, secara parsial nilai tukar rupiah berpengaruh signifikan dan negatif terhadap cadangan devisa Indonesia

Uji t variabel Utang Luar Negeri diperoleh nilai t hitung sebesar 5.091 sedangkan nilai t tabel 
( $\alpha / 2-0.025)$ dengan deegre of freedom (df) adalah 11 (n-k-1) sehingga diperoleh t tabel sebesar 2,2009. Berdasarkan hasil tersebut diketahui bahwa nilai $\mathrm{t}$ hitung 5.091 > t tabel 2.2009. Artinya, secara parsial utang luar negeri berpengaruh signifikan dan positif terhadap cadangan devisa Indonesia.

\section{Pengaruh Ekspor Terhadap Cadangan Devisa Indonesia}

Berdasarkan hasil analisis secara parsial, kesimpulan yang dapat ditarik adalah variabel ekspor berpengaruh signifikan dan positif/ searah terhadap cadangan devisa Indonesia.

Hal ini dapat terjadi karena dengan dilakukannya kegiatan ekspor mendatangkan valuta asing yang menambah cadangan devisa yang hal ini didukung dengan teori Todaro (2011) yang mengatakan kegiatan ekspor pasti akan mendatangkan valuta asing/devisa. Semakin sering transaksi ekspor maka semakin banyak pula devisa yang masuk.

Kajian ini selaras dengan pengamatan yang terlebih dahulu dilakukan Kuswantoro (2017) yang juga menunjukkan bahwa ekspor berpengaruh signifikan dan positif terhadap cadangan devisa Indonesia.

\section{Pengaruh Nilai Tukar Rupiah Terhadap Cadangan Devisa Indonesia}

Hasil analisis menunjukkan bahwa secara parsial variabel nilai tukar rupiah berpengaruh signifikan dan negatif terhadap cadangan devisa Indonesia. Yang dimaksud negatif adalah ketika nilai tukar rupiah terhadap dollar naik maka cadangan devisa Indonesia akan menurun dan sebaliknya. Sesuai dengan Kuswantoro (2017) yang menyebutkan bahwa ketika nilai tukar rupiah menguat dan dengan adanya stabilisasi ekonomi dan meningkatnya minat investor, cadangan devisa juga akan meningkat seiring dengan peningkatan surplus.

\section{Pengaruh Utang Luar Negeri Terhadap Cadangan Devisa Indonesia}

Berdasarkan hasil analisis yang dilakukan, secara parsial variabel utang luar negeri berpengaruh signifikan dan positif terhadap cadangan devisa Indonesia.

Hal ini dapat terjadi sebab pada awalnya setiap pinjaman luar negeri akan menambah cadangan devisa namun juga akan menambah akumulasi utang yang harus dibayar yang juga didanai dari cadangan devisa. Temuan ini sama dengan Kuswantoro (2017) yaitu utang luar negeri berpengaruh signifikan dan positif terhadap cadangan devisa Indonesia.

\section{KESIMPULAN DAN SARAN}

\section{Kesimpulan}

1. Variabel Ekspor berpengaruh signifikan dan positif terhadap Cadangan Devisa Indonesia.
Artinya, meningkatnya ekspor mendukung kenaikan cadangan devisa Indonesia.

2. Variabel Nilai Tukar Rupiah berpengaruh signifikan dan negatif terhadap Cadangan Devisa Indonesia. Artinya, penurunan nilai tukar rupiah atau apresiasi nilai tukar rupiah mendukung kenaikan cadangan devisa Indonesia.

3. Variabel Utang Luar Negeri berpengaruh signifikan dan positif terhadap Cadangan Devisa Indonesia. Artinya, bertambahnya utang luar negeri mendukung kenaikan cadangan devisa Indonesia.

\section{Saran}

1. Pemerintah dan Bank Indonesia diharapkan selalu menjaga dan meningkatkan stabilitas nilai tukar rupiah dengan melakukan intervensi pasar agar terjadi surplus pada transaksi berjalan dan juga bertambahnya cadangan devisa.

2. Bank Indonesia selaku bank sentral diharapkan agar terus mejaga kondisi cadangan devisa Indonesia agar transaksi internasional dapat terus berlangsung dengan stabil dan lancer.

\section{DAFTAR PUSTAKA}

Amir MS. 2004. Strategi Memasuki Pasar Ekspor. Jakarta: Lembaga Manajemen PPM Dan Penerbit PPM.

Atmadja, Adwin Surya. 2000. "Utang Luar Negeri Pemerintah Indonesia: Perkembangan Dan Dampaknya (Adwin Surya Atmadja) Utang Luar Negeri Pemerintah Indonesia: Perkembangan Dan Dampaknya." Akuntansi Dan Keuangan 2(1): 83-94. Http://Puslit.Petra.Ac.Id/Journals/Accounting /.

Case, Karl E; Fair, Ray C. 2007. Prinsip-Prinsip Ekonomi. Jilid 1. Jakarta: Erlangga.

Gandhi, Dyah Virgoana. 2006. Seri Kebanksentralan Pengelolaan Cadangan Devisa Di Bank Indonesia. Jakarta: Bank Indonesia.

Ghozali Imam. 2013. Metode Penelitian Bisnis Aplikasi Analisis Multivariat Dengan Program IBM SPSS 21.Edisi 7, Penerbit Universitas Diponegoro, Semarang. Semarang: Penerbit Universitas Diponegoro.

Habibi, Ach., And Wahyu Hidayat R. 2017. "Analisis Pengaruh Economic Freedom Terhadap Foreign Direct Investment Di Negara Asean.” Jurnal Ekonomi Pembangunan 15(1): 87.

Hady, Hamdy. 2004. Ekonomi Internasional Buku 1 Edisi Revisi: Teori Dan Kebijakan Perdagangan Internasional. Jakarta: Ghalia 
Indonesia.

Halwani, Hendra. 2005. Ekonomi Internasional Dan Globalisai Ekonomi. Edisi Kedu. Bogor: Ghalia Indonesia.

I Putu Kusuma Juniantara, And Made Kembar Sri. 2013. "Pengaruh Ekspor, Impor Dan Kurs Terhadap Cadangan Devisa Nasional Periode 1999-2010." Journal Of Chemical Information And Modeling 53(9): 1689-99.

Irawan, And Suparmoko. 2016. Ekonomika Pembangunan. Yogyakarta: BPFE.

Jalunggono, Gentur, Yulia Tri Cahyani, And Whinarko Juliprijanto. 2020. "Pengaruh Ekspor, Impor Dan Kurs Terhadap Cadangan Devisa Indonesia Periode Tahun 2004 2018." Jurnal Ekonomi, Bisnis, Dan Akuntansi 22(2): 171-81.

Kuswantoro, Muchammad. 2017. “Analisis Pengaruh Inflasi, Kurs, Utang Luar Negeri Dan Ekspor Terhadap Cadangan Devisa Indonesia." Tirtayasa Ekonomika 12(1): 146.

Machmud, Amir. 2016. Perekonomian Indonesia : Pasca Reformasi. Jakarta: Erlangga.

Majid, M Khairin. 2013. “Analisis Pengaruh Utang Luar Negeri Dan Penanaman Modal Asing Terhadap Produk Domestic Bruto." Jurnal Ilmiah Universitas Brawijaya.

Mankiw N, Gregory. 2007. Makroekonomi Edisi Keenam. Jakarta: Erlangga.

2012. Pengantar Ekonomi Makro. Jakarta: Salemba Empat.

Manurung, Adler Haymans. 2016. Cadangan Devisa Dan Kurs Valuta Asing. Jakarta: Kompas Media Nusantara.

Murni, Asfia. 2016. Ekonomika Makro Edisi Revisi. Bandung: PT. Refika Aditama.

Purwito, Ali, And Indriani. 2015. Ekspor, Impor, Sistem Harmonisasi, Nilai Pabean Dan Pajak Dalam Kepabeanan. Jakarta.

Putri, H., T. Indrawati, And A. Widayatsari. 2017. "Pengaruh Ekspor, Penanaman Modal Asing, Dan Utang Luar Negeri Terhadap Cadangan Devisa Di Indonesia." Jurnal Online Mahasiswa Fakultas Ekonomi Universitas Riau 4(1): 240-52.

Reny, And Agustina. 2014. "Pengaruh Ekspor, Impor, Nilai Tukar Rupiah, Dan Tingkat Inflasi Terhadap Cadangan Devisa Indonesia." Jurnal Wira Ekonomi Mikroskil 4(2): $\quad$ 61-70. Https://Www.Mikroskil.Ac.Id/Ejurnal/Index. Php/Jwem/Article/View/214/137.
Salvatore, Dominick. 2014. Ekonomi Internasional. Edisi 9. Jakarta: Salemba Empat.

Santana, Made, And Putra Adiyadnya. 2017. "Suku Bunga Kredit Dan Utang Luar Negeri Terhadap Cadangan Devisa Indonesia Tahun 1996-2015." Juara 7(1): 68-78. Http://Jurnal.Unmas.Ac.Id/Index.Php/JUAR A/Article/View/648/599.

Sonia, Agnes Putri, And Nyoman Djinar Setiawina. 2016. "Pengaruh Kurs , Jub Dan Tingkat Inflasi Terhadap Ekspor , Impor Dan Cadangan Devisa Indonesia Fakultas Ekonomi Dan Bisnis Universitas Udayana ( Unud ), Bali , Indonesia Perdagangan Internasional Berperan Penting Untuk Memenuhi Kebutuhan Negara Di Dunia ." 5: 1077-1102.

Subandi. 2008. Sistem Ekonomi Indonesia. Bandung: Alfabeta.

Sugiyono. 2011. Metode Penelitian Kuantitatif, Kualitatif Dan R\&D. Bandung: Afabeta.

Sukirno, Sadono. 2008. Makroekonomi Teori Pengantar. Jakarta: PT. Raja Grafindo Persada.

. 2015. Makroekonomi Teori Pengantar. Jakarta: PT. Rajagrafindo Persada.

Tambunan, Tulus. 2001. Perekonomian Indonesia Teori Dan Temuan Empiris. Jakarta: Ghalian Indonesia.

Todaro. 2011. Pembangunan Ekonomi. Edisi Sebe. Jakarta: Erlangga.

Togatorop, Sahat Marulitua, And Nyoman Djinar Setiawina. 2017. "Pengaruh Utang Luar Negeri, Net Ekspor, Dan Belanja Wisatawan Mancanegara Terhadap Cadangan Devisa Di Negara Indonesia Tahun 1994-2013.” Jurnal Ekonomi Pembangunan Universitas Udayana 6. 